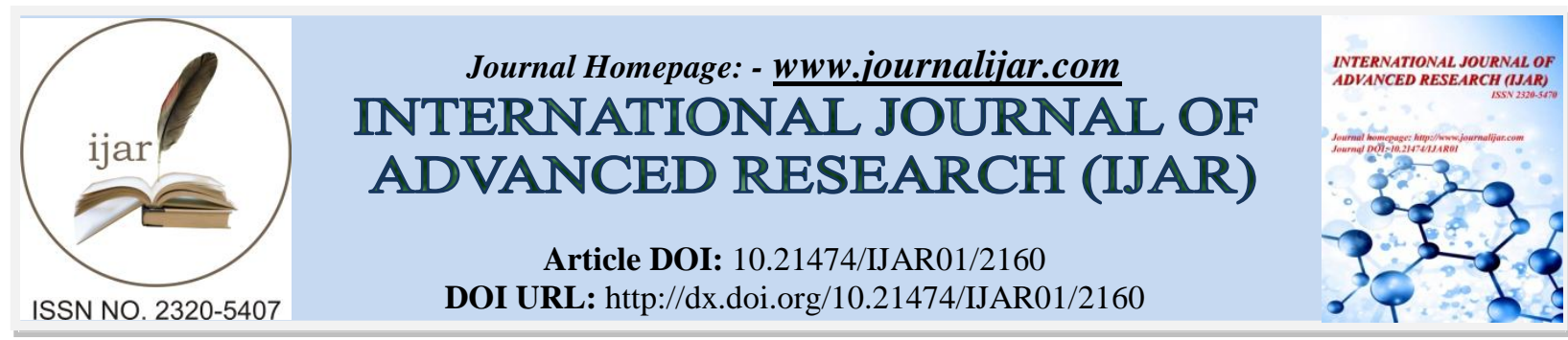

RESEARCH ARTICLE

\title{
CONCEPTUAL DESIGN AND INTRODUCING PROPER TRACTOR MOUNTED PALM LIFTER USING ANALYTICAL HIERARCHY PROCESS (AHP)
}

Mostofi Sarkari, Mohammad Reza.

Department of Power and Farm Machinery Engineering, Agricultural Engineering Research Institute, Agricultural Research, Education and Extension Organization, Tehran, Iran.

\section{Manuscript Info}

Manuscript History

Received: 26 September 2016

Final Accepted: 29 October 2016

Published: November 2016

Key words:-

AHP, conceptual design, dates, palm,

Selection, tractor mounted lifter machine.

\section{Abstract}

Because of palm lifter (service) shortage, a mechanized approach does not exist to cover all farmer needs, and usually most of palm production applications in the world were performed manually. All field operations (services) which is done using the palm lifter are as follows: 1- To pruning leaves and bottom leaves, 2- Pollination, 3cluster thinning, 4- pack the clusters, and 5- moving clusters, 6spraying, and 7- harvesting.

This study was conducted in three phases; In phase one, province surveying were applied to gain technical information from current machine in palm cultivation and harvesting application in five provinces and prepared questioner contained palm geometric characteristics such as height and row spacing (density) and time limit of the palm lifter application in cultivation and harvesting were recorded. The analysis of the measured data show that in more than $75 \%$ of the objected provinces of date palm orchards, palms have a height of 10 to 12 meters. In the second phase, based on the analytical hierarchy process (AHP) a proper palm lifter was selected between seven domestic and foreign (imported) machine. The results showed that despite of imported palm lifter (Magny and Italian), AERI prototype lifter is chosen as a proper one. In the third phase, the conceptual design of prototype machine was performed based on gained information and the machine will be had advantages of existing machinery and lowest disadvantages of them.

Copy Right, IJAR, 2016,. All rights reserved.

\section{Introduction:-}

The acreage of palm orchards under consideration of scattered trees has been estimated about 244 thousand hectares in 2011 that $83.8 \%$ and $16.2 \%$ of them are fertile and no fertile (seedlings), respectively. $91.2 \%$ of about 205 thousand hectares of fertile trees is irrigated. The highest fertility levels of palm in the country belong to Sistan and Baluchistan province with 17\%. Bushehr, Hormozgan, Jiroft and Kahnouj region, Khuzestan, Kerman and Fars are located the percent of $7.15,16,15.5,13.2,11,10.1$, respectively of the fertile palm acreage in next positions. These seven mentioned provinces have the fertility levels of $98.4 \%$. Palm production rate was estimated around 1 million tons by Agricultural statistics (2010) that 95.6 percent of them has been made of the irrigated lands. The fraction of dry lands was $4.4 \%$. Despite the Jiroft region ranks fourth in fertility levels is located first of palm production with 
19.8\%. The provinces of Khuzestan, Sistan and Baluchistan, Hormozgan, Bushehr, Kerman and Fars are located in the next places with the percent fractions of 15.2, 14.1, 15.1, 13.5, 12.2 and 9.8, respectively. Seven mentioned provinces produce 99.6 percent of the date palms.

Saaty and Bagheri Nejhad and Adibi (1994 and 1980) and (2010) AHP technique allows to express of the issue for the Analytical Hierarchy Process and weight down based on Pair wise comparison criteria. This technique has many applications. One of the methods of analysis and evaluation is multi-criteria decision, which is widely used in earth sciences and space planning and the environment. Analytical Hierarchy Process was invented in the early 70s by a clock. The process was introduced to assign rare resources as well as for military planning need by the clock, and later was used by different researchers in the evaluation and planning. AHP has to be one of the most used methods of multi-criteria decision since its introduction and to solve unstructured problems in different areas of interests and human needs, such as politics, economics, social sciences and management.

An example of the research results on the analytical hierarchy process to choose a machine is presented as follows:-

A study entitled "Determining the needs of Iran-Khodro Diesel Company customers using fuzzy AHP approachCase Study (Iran-Khodro Diesel Company, buses C457)" was performed by Madhoosh et al (2004) showed that focusing on customer needs and comply them more highlight on the quality of the product and, therefore, on the level of customer satisfaction. AHP process helps to evaluate and improve the product's development stage.

"A model based on analytical hierarchy process to select a placement tactics of management systems Region" was reported by Barzghar et al (2007) to examine implementing the model in the industry and mining Bank, internal development of the organization and with more customization subcriteria and buying with ordering are affected mostly by the complexity of the process. This means that if the complexity of the process is high in this organization, or enterprise resource planning system should be developed within the Bank or have bought a system that can be customized and adjusted for alignment with the company's processes.

The results of a study was done by Aghajani Bazazi et al (2008) entitled as "the application of multiple criteria decision methods to select loading and handling car for Sungun copper mine explained the effective reasons in the decision making process to select the surface mining machines and was calculated weights of the criteria using AHP and then selected the best loading and copper mine Sungun using TOPSIS. The results of this study showed that calculation time and decision-making was reduces significantly using this method.

In the study of "Compilation models to assess the organization's readiness to set up a data warehouse system using the Analytical Hierarchy" carried out by Bagheri Nezhad and Adibi (2010) found the criteria and subcriteria to evaluate the readiness of organizations to carry out data warehouse system and performing confirmation and test theory, the importance degree of each criteria are different and finally an integrated model with relevant 6 main criteria and 23 subcriteria is presented. The proposed model is of high legality.

The study titled "Locating wind power plants using Analytical Hierarchy Process (AHP) in GIS" performed Morshedi et al (2010) settled that GIS as a decision support system, can prepare the data and in the Priority is highly efficient and expert opinions for various causes and help designers in choosing a suitable location for power plant construction. Also, the Analytical Hierarchy Process (AHP) has high flexibility than other methods of for model the logical relations common influence on each other's features.

Shahanaghi (2011) in the study as entitled "Designing a model based on MCDM decision to outsource maintenance and repairs" were announced what activities and when to outsource, to make more profit organizations. Therefore, by entering the age position systems and equipment, the time factor involved in the outsourcing decision process and the effect of future changes in is considered terms of today decision.

Perkins and Brown (1964) started their research with USDA Agricultural Engineering and University of California to commercialize mechanical harvesting methods with the aim of lessening the number of workers and savings costs for palm producers in California. It is predicted that 65\% of Year 1965-66 are harvested with the help of mechanical systems, which would have reduced 50 to 80 percent, compared with the manual conventional harvesting method. The results pointed out labor needs of mechanical harvesting systems are already 20 to 50 percent of conventional manual harvesting needs to harvest 1,000 pounds $(453.6 \mathrm{~kg})$ dates. Currently, the elevators as forklift are used which 
perform cultivation and harvesting operations separately and are attached to basket (Al-Khafaf, 1970). The progress of the past decade in mechanization of farming practices of palm was focused on mechanical harvesting. According to Al-Khafaf, in all parts of the world where are rich in palm, harvesting cost is high and the use of machines was so prevalent before 1966, the cost of harvesting included more than $45 \%$ of fruit orchards, but the cost caused by employing workers were significantly decreased by the power of using machine. For example, in the United States could be harvested dates exceed $80 \%$ by machine and reducing workers need to $20 \%$.

Brown and Perkins (1964) reported the manually lightweight (7-8 kg) machines were used at the beginning for the harvest. The power of these machines was high $(1400 \mathrm{rpm})$. Worker was climbing the tree either using the machine or by himself and attached the end cluster of fruit to the machine with help of levers and hooks then turned it on. Ripe fruits were falling into the basket because of the severe vibrations to the cluster. This technique is used mainly to harvest the ripe fruits, but in Iran, the workers use the benefit of the leg or piece of wood. According to their reports, the moving conveyor was used in the palm orchards of America to harvest.

Perkins and Brown (1964) there was needed 60 hours of continuous work for harvesting 12 tons of palms from one hectare of palm trees with common method in the United States (10 employees at 6 hours daily) is, but using fully automatic conveyor towers was not necessary more than 4 hours. Harvesting costs could be reduced considerably and increased revenues garden owners, by comparing these methods and to apply the simplified system.

Thwainy et al (1993) in presenting the results of design, make and evaluation of palm service machines (As forklifts and usable for individual palms) reported all new palm services machines has good potential for further investigation.

Akyurt et al (2002) reported in a study with the title of "evaluation of the mechanization needs in crown operations of palm tree" the most proper palm service machine was combining climbing capacity with forklift by manufacturing user platform trailer with clamps to hold the product in palm height of 4 to 15 meters aboveground. Therefore, the part of the palm crown, trailer and lifter can be flexible and practical approach for the palm mechanization.

Moustafa (2005) in a study entitled "Development palm Service tractor-mounted machines" evaluated and test the machine. Compared with traditional methods and use of the lifter tractor mounted pointed to the usable of the machine and increase the productivity of the workers.

Shamsi (2011) a lightweight four-wheeled machine that climbed the tree was built in Cranfield University in England, with the ability of solving harvest problem and pollinators. This machine can move on land and between the palm trees with its power and goes up the tree trunk. This machine have superior features compared with other machines such as tree climbing proper speed and low weight and the capacity to withdraw a tree in 22 minutes and caused no danger for the workers and the tree.

Generally, selecting and introducing a sample machine, which is particularly necessary for mechanizing Palm orchards, and has capability to manufacture in the country and there is no need to import, Analytical Hierarchy Process (AHP) can be helpful to chose wisely. Field-testing would be done correctly after design and construct a prototype machine, then proceed semi-mass and industrial production. The project objectives were:

1) Field survey to measure design technical features of tractor mounted lifter machine,

2) Analytical hierarchy process for the selection and introduction of prototype machine,

3) Conceptual design of the most suitable palm lifter machine for date palm orchards.

\section{Material and Method:-}

Provincial surveying were performed to get the technical information of how to use the pruned leaves and stubs machines for five major palm producing provinces including: 1. Sistan and Baluchestan, 2. Jiroft and Kahnooj, 3. Fars, 4. Kerman, 5. Khuzestan. A questionnaire was prepared to record data consisting of palm cultivation information and the geometry and the time limit of machine to cultivation (pruning). After identifying the basic information, project stages will be started to instrument.

Because of the lack of skilled workers to performing palm agricultural operations in the field and incapable ordinary to carry out the operation such as tree climbing at an average speed of $0.31 \mathrm{~ms}^{-1}$, stepping on mechanizing these 
actions is one of the essential needs in palm production industry. According to all palm agricultural operation is not possible without participating workers above the tree (bending and closing clusters and thinning more fruit), behind tractor, lifter for mechanized services will be designed and construct to perform all the procedures. The present study was conducted in three phases:

a) A provincial surveying to take infrastructure data for design and construction of the palm tractor mounted lifter: Measuring the height of the dominant palm cultivations of palm-prone areas in the purpose provinces, the distance between the rows and in the rows and calculate density and number of trees per hectare

b) Selecting suitable palm lifter machine (Services) for five major producer provinces using Analytical Hierarchy Process (AHP) - Criteria and sub-criteria were codified for seven lifter machines and by Expert Choice software. Studied machines were: Lajvar, Snow Pars, Kaveh Fars, Malaysia, Iranian (farmer), Magny-Italian, AERI (Agricultural Engineering Research Institute) prototype machine. Sub-criteria, which were evaluated including: How to connect the tractor, working height, basket capacity, weight and machine price.

c) Conceptual design of tractor mounted lifter prototype; about the tractors MF399, U650 and JD-3140 in most gardens, tractor was the supply power, which is equipped to a hydraulic system with an output of at least double and the lifter device is tractor mounted and rotates 270 degrees and served at least two or four palms in one positioning. Designed lifter has an attached U cabin and the five palm service operations will be carried out from the cabin. This Cabin has a hydraulic system capable of taking angle over the palm tree. Weight transfer theory, doubling the rear wheels, increasing the width front and rear axles and adding counterweights to the front of the tractor are employed to balance lifter machine.

\section{Results and Discussions:-}

\section{Provincial surveying:-}

The results of measurements' analysis of garden geometric features to achieve the principles of palm lifter design to separating target regions are as follows:

Table 1:- Results of the Analysis of Geometric Features of Khuzestan Province Date Palm Orchards

\begin{tabular}{|c|c|c|c|c|}
\hline \multicolumn{5}{|c|}{ Khuzestan Province } \\
\hline \multirow[t]{2}{*}{ Whole province } & \multicolumn{3}{|c|}{ Variety } & \multirow{2}{*}{$\begin{array}{c}\text { Measured and } \\
\text { calculated } \\
\text { features }\end{array}$} \\
\hline & Ghontar & Kabkab & Estamaran & \\
\hline $\begin{array}{c}98.7 \% \text { up to } 10 \mathrm{~m} \\
30807 \mathrm{ha}\end{array}$ & $100 \%$ up to $8 \mathrm{~m}$ & $94.4 \%$ up to $10 \mathrm{~m}$ & $\begin{array}{l}66 \% \text { up to } 8 \mathrm{~m} \\
34 \% \text { up to } 10 \mathrm{~m}\end{array}$ & Palm height \\
\hline $83.1 \%$ up to $8 \mathrm{~m}$ & $66.7 \%$ up to $7 \mathrm{~m}$ & $100 \%$ up to $6 \mathrm{~m}$ & $75.5 \%$ up to $8 \mathrm{~m}$ & $\begin{array}{c}\text { Distance on the } \\
\text { row }\end{array}$ \\
\hline $98.7 \%$ up to $9 \mathrm{~m}$ & $\begin{array}{l}66.7 \% \text { up to } 8 \mathrm{~m} \\
33.3 \% \text { up to } 9 \mathrm{~m}\end{array}$ & $\begin{array}{l}72.2 \text { up to } 6 \mathrm{~m} \\
27.8 \text { up to } 7 \mathrm{~m}\end{array}$ & $98.1 \%$ up to $9 \mathrm{~m}$ & $\begin{array}{c}\text { Distance between } \\
\text { the row }\end{array}$ \\
\hline
\end{tabular}

Data analysis in Table 1 show the average height of the region dominant cultivations which form $98.7 \%$ of the under cultivation area (30807 hectares) is up to 10 meters which include up to 8, 10 and 8 meters for Estemaran, Kabkab and Gantar, respectively.

Table 2:- Results of the Geometric Features Analysis of Sistan and Baluchestan Province Date Palm Orchards

\begin{tabular}{|c|c|c|c|}
\hline \multicolumn{4}{|c|}{ Sistan \& Baluchistan Province } \\
\hline \multirow[t]{2}{*}{ Whole province } & \multicolumn{2}{|c|}{ Variety } & \multirow{2}{*}{$\begin{array}{c}\text { Measured and } \\
\text { calculated features }\end{array}$} \\
\hline & Rabbi & Mozafati & \\
\hline $\begin{array}{c}84 \% \text { up to } 12 \mathrm{~m} \\
30113 \mathrm{ha}\end{array}$ & $\begin{array}{c}57.4 \% \text { up to } 8 \mathrm{~m} \\
31.9 \% \text { more than } 12 \mathrm{~m}\end{array}$ & $85.1 \%$ up to $8 \mathrm{~m}$ & Palm height \\
\hline $88.3 \%$ up to $8 \mathrm{~m}$ & $85.1 \%$ up to $8 \mathrm{~m}$ & $91.5 \%$ up to $8 \mathrm{~m}$ & Distance on the row \\
\hline $96.8 \%$ up to $10 \mathrm{~m}$ & $\begin{array}{l}63.8 \% \text { up to } 8 \mathrm{~m} \\
36.2 \% \text { up to } 10 \mathrm{~m}\end{array}$ & $83 \%$ up to $8 \mathrm{~m}$ & Distance between the row \\
\hline
\end{tabular}

The results of data analysis in Sistan and Baluchistan, Table 2, shows the average height of the region dominant cultivations which form $84 \%$ of the under cultivation area (30113 hectares) is up to 12 meters which include up to 8 , and 8-12 meters for Mazafati and Rabbi, respectively. 
Table 3:- The Results of the Geometric Feature Analysis of Kerman Province Date Palm Orchards

\begin{tabular}{|c|c|c|c|}
\hline \multirow{2}{*}{ Whole province } & \multicolumn{2}{|c|}{ Kerman Province \& South Kerman Region } & \multicolumn{1}{|c|}{$\begin{array}{c}\text { Measured \& } \\
\text { Calculated features }\end{array}$} \\
\cline { 2 - 4 } & Zahedi & $88.9 \%$ up to $6 \mathrm{~m}$ & Palm height \\
\hline $\begin{array}{c}94.5 \% \text { up to } 12 \mathrm{~m} \\
60055 \mathrm{ma}\end{array}$ & $\begin{array}{c}70 \% \text { up to } 12 \mathrm{~m} \\
30 \% \text { more than } 12 \mathrm{~m}\end{array}$ & $87.8 \%$ up to $8 \mathrm{~m}$ & Distance on the row \\
\hline $90 \%$ up to $8 \mathrm{~m}$ & $90 \%$ up to $6 \mathrm{~m}$ & $\begin{array}{c}75.6 \% \text { up to } 10 \mathrm{~m} \\
24.4 \% \text { more than } 10 \mathrm{~m}\end{array}$ & Distance between the row \\
\hline $80 \%$ up to $10 \mathrm{~m}$ & $90 \%$ up to $8 \mathrm{~m}$ & & \\
& & &
\end{tabular}

Data analysis in Kerman province, Jiroft and Kahnooj region (south of Kerman), Table 3, show the average height of the region dominant cultivations which form $94.5 \%$ of the under cultivation area (60055 hectares) is up to 12 meters which include up to 6 and 12 meters for Mazafati and Zahedi (Ghosab), respectively.

Table 4:- Analysis of Geometric Features in Fars Province Date Palm Orchards

\begin{tabular}{|c|c|c|c|c|}
\hline \multicolumn{3}{|c|}{ Fars Province } & \multirow{2}{*}{ Measured and calculated features } \\
\hline \multirow{2}{*}{ Whole province } & Zahedi & Kabkab & Shahani & Palm height \\
\cline { 2 - 4 } & $8-10 \mathrm{~m}$ & Up to $10 \mathrm{~m}$ & $8-10 \mathrm{~m}$ & \\
\hline $\begin{array}{c}67 \% 10-11 \mathrm{~m} \\
18670 \mathrm{ha}\end{array}$ & & & & \\
\hline
\end{tabular}

Data analysis in Fars province, Table 4, point to the average height of the region dominant cultivations which form $67 \%$ of the under cultivation area (18670 hectares) is up to 11 meters which include up to $8-10,10$, and 11.5 meters for Shahani, Kabkab and Zahedi (Ghosab), respectively.

\section{Selecting and introducing machine based on Analytical Hierarchy Process (AHP):-}

In the first step, criteria and sub-criteria are identified and placed in a hierarchical structural analysis layout (Fig.1) and weighted with each other (Fig.2). Pair wise comparison is performed after the final assessment of sub-criteria. For weighting the criteria, each of them was compared pair wise according to the experts' sights for were and a concession was awarded to each based on its preference and importance and finally, according to the preferences, the final weight of each criterion and its importance were determined in decision-making. In addition, scoring are performed on to preferred values, which shown in the Table 5.

Table 5:- Preferred Values for Paired Comparisons

\begin{tabular}{|c|c|c|}
\hline Values & Preferred \\
\hline 9 & Extremely Preferred \\
\hline 7 & Very Strongly Preferred \\
\hline 5 & Strongly Preferred & \\
\hline 3 & Moderately Preferred & \\
\hline 1 & Equally Preferred & \\
\hline $8,6,4,2$ & Between the Preferred Steps \\
\hline
\end{tabular}

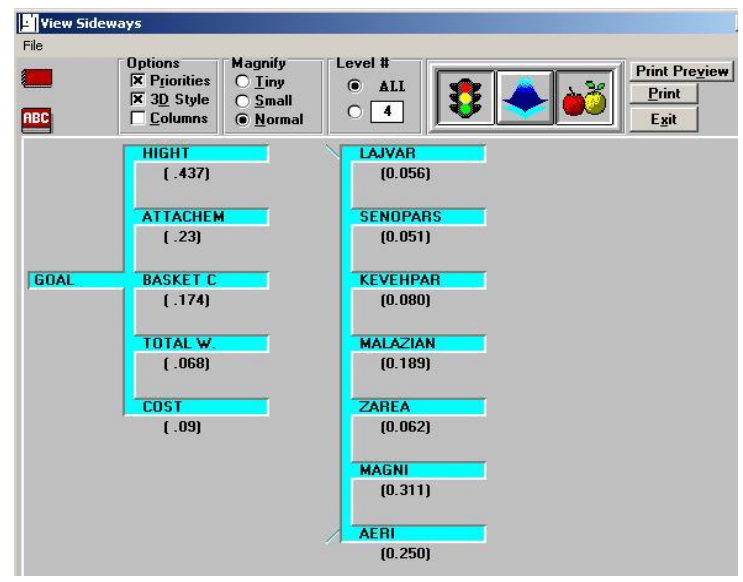

Figure 1:- Flowchart of Criteria and Sub-criteria in Analytical Hierarchy Process (AHP). 


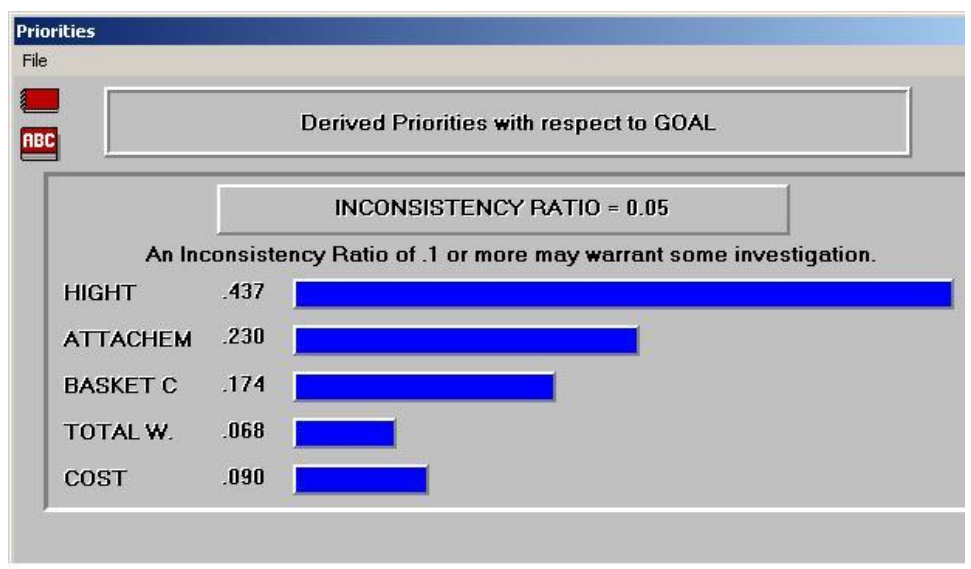

Figure 2:- Weight of Each the Sub-criteria Compared To the Selected Criteria.

As seen in Fig. 2, the height alternative (lifter rising) has been of particular importance in this design and so involves a high weight percentage (43.7\%). The second choice is about how to connect the machine to the tractor and the machine could be trailed, mounted and autonomous tractor and was assigned $23 \%$ of importance weight to them. Next case was the lifter basket capacity that can be in $\mathrm{V}$ or $\mathrm{U}$ shapes and has a hydraulic output equipment and winch to connect pruning, spraying, pollination and fruit transition to the bottom (17.4\%), respectively. The overall weight of the machine (6.8\%) is also great importance, so that's not caused soil compaction in the garden and can travel between Palms and lessen the damages between the trees. Finally, the lifter machine price was in fourth place (9\%) and despite its economical importance for users and operators, it is not more important than the technical features.

In the second step, the criteria were selected for the seven palm lifters machines, weighted based on their importance and compared to each other as seen in Fig.3.

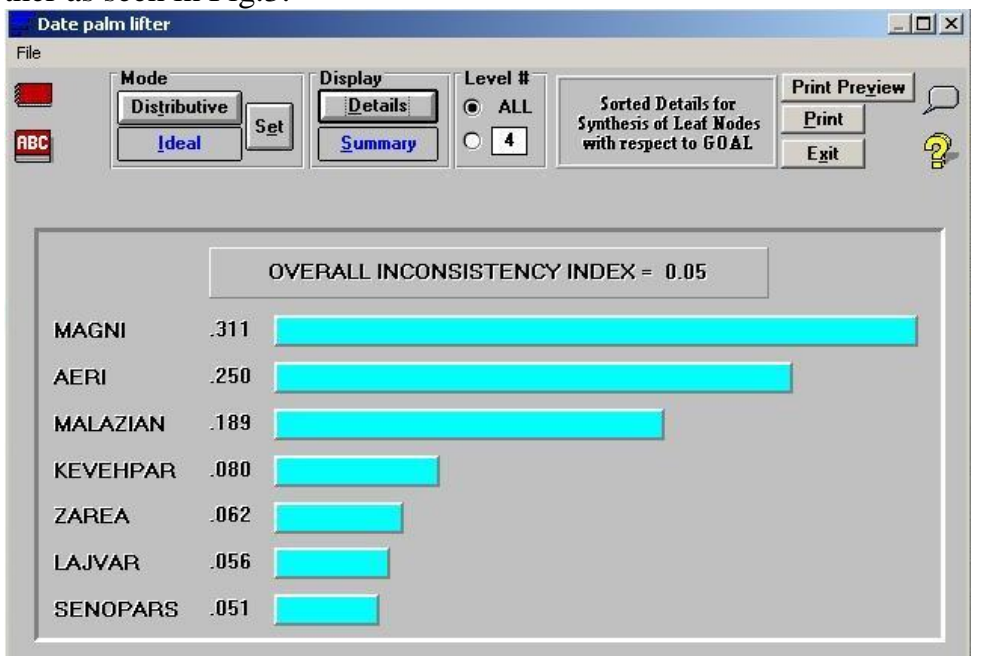

Figure 3:- Criteria and Their Weights Compared To the Least Conflict (5\%).

As seen in Fig.3, the first weight place was for Magny-Italian Autonomous lifter and assigned the greatest potential among the target machines. Second place was for the technical and AERI prototype machine, the subject of this article, design and construction is scheduled to be planned so it's tractor mounted and take the power from the hydraulic output and service for two to four palm. Malaysia is the next palm lifter, which is Autonomous machine and lifter mounted on a truck and is used for cultivation and harvesting operations.

Pair wise comparison of criteria and sub-criteria was done according to the experts' opinions, its data was entered the Expert Choice software and were analyzed, and the results were shown in Figs. 4 to 8. 


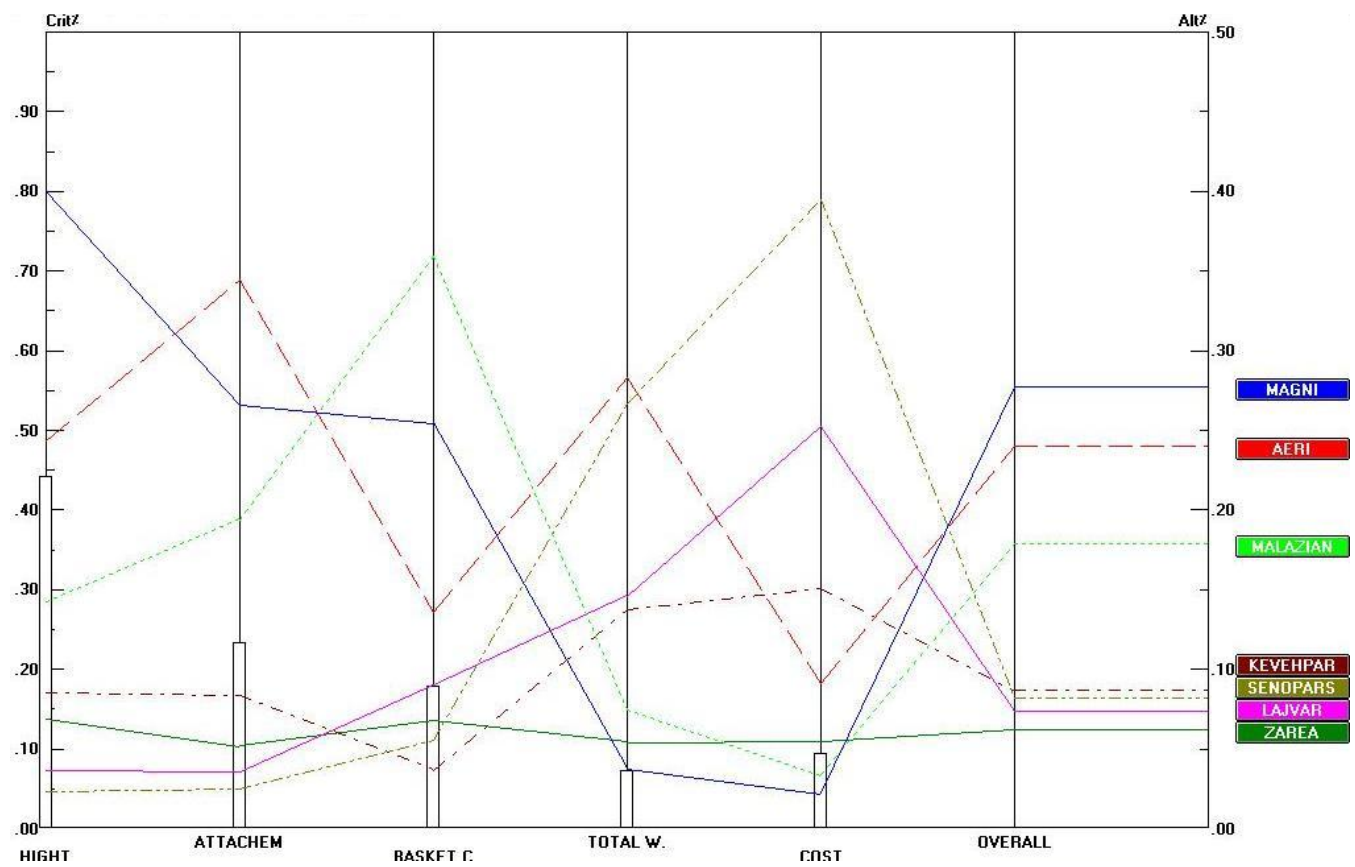

Figure 4:- Sensitivity Analysis to Select the Proper Machine.

Sensitivity analysis showed that despite high price of Magny-Italian lifter machine because of its autonomous feature, suitable high altitude, maneuverability between trees and acceptable basket capacity has been ranked first and chosen in top machine. Next Level is confined to AERI prototype machine and if we consider the project economically because of the cost and be a domestic production of it, this machine is placed first. Finally, the third place is accounted for imported Malaysians machine that despite the positive technical parameters because of truck mounted, suitable basket capacity and lack of maneuverability between trees is placed in the rank after the AERI prototype machine.

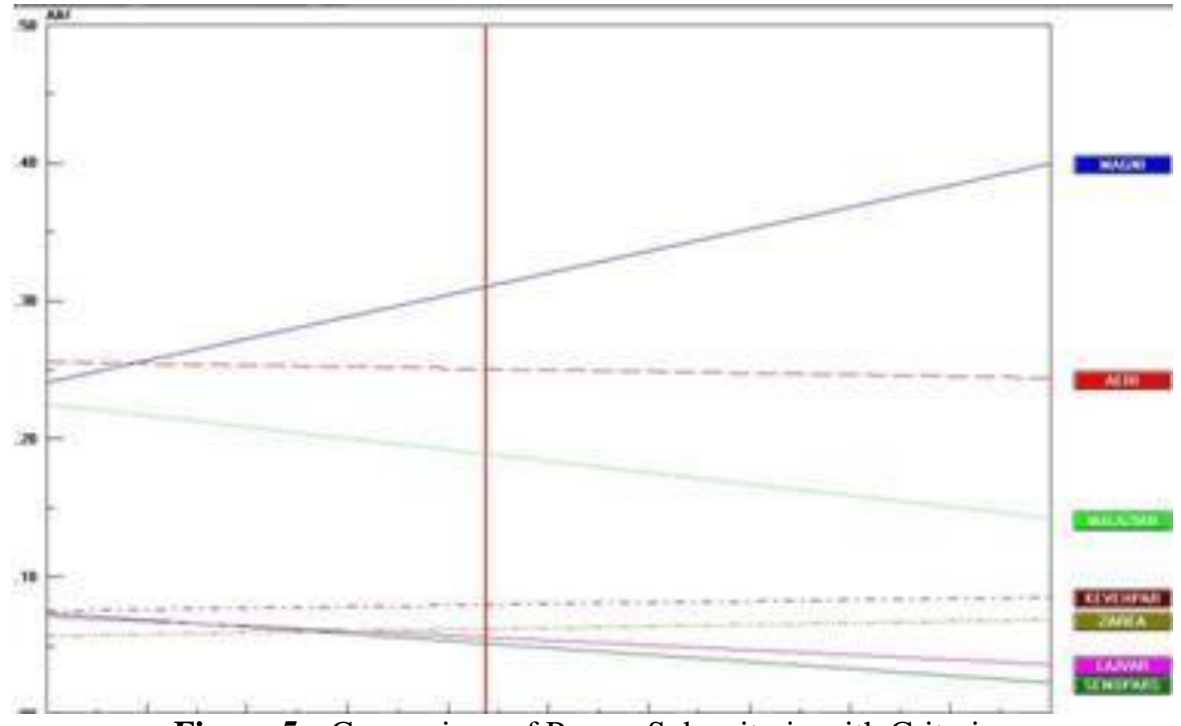

Figure 5:- Comparison of Proper Sub-criteria with Criteria.

About to the particular importance of lifter height, so the machines of Italian Magny-, AERI prototype machine and Malaysian (Fig.5) were ranked first, second and third, respectively based on technical and functional parameters. 


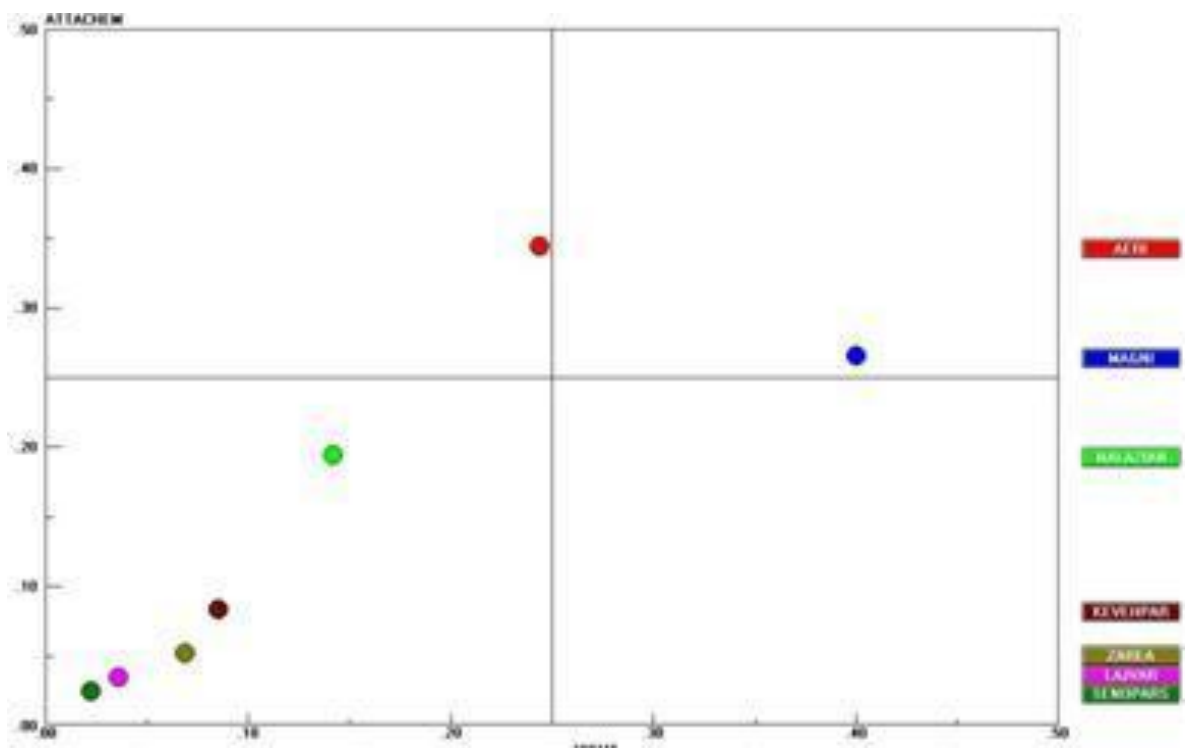

Figure 6:- Comparison of Sub-criteria Proper Height and How to Install to Tractor.

Fig.6 shows a typical AERI machine which is ranked first because of its connection to the tractor, using the tractor hydraulic system as a power source and the availability of the tractor in most date palm gardens, and Italian Magny and Malaysia are in the next ranks. Another advantage of AERI prototype machine is because of having 270-degree rotation system, which services two or four palm trees at once fitting in the garden. Also, Fig.6 shows the Magny option because it is located at the top right of the graph earned the most points from the user according to both available criteria in the vertical and horizontal axis. AERI prototype machine has gained the most points of all subcriteria from the perspective of connection but in the view of height earns a lower rating than Magny as designed in the height of 12 meters for date Palm, thus is located in the top left graph division. The next sub-criteria have taken place in the left bottom sector, so because of height and connectivity criteria are not taken account as good subcriteria compared to two mentioned sub-criteria.

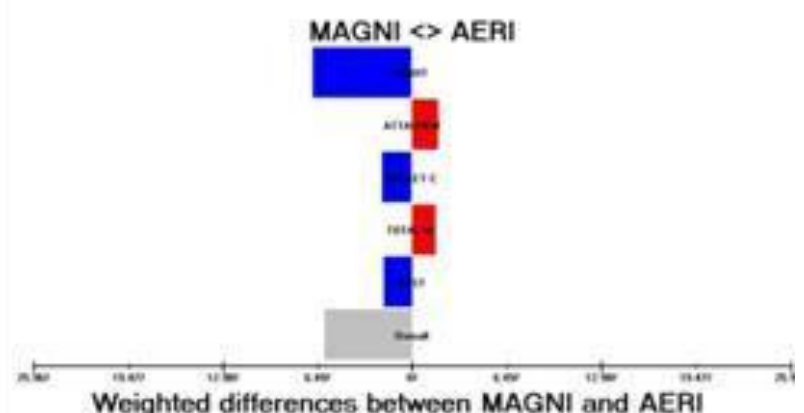

Figure 7:- Compared Machine Weight Difference with Consideration of the Sub-criteria.

The comparison between Italian Magny lifter machines and AERI prototype machine (Fig.7) showed the differences between the two machines of how to connect (tractor mounted and autonomous) and the overall weight and climbing height with the least conflict of $5 \%$. Other criteria have almost the same advantages. 


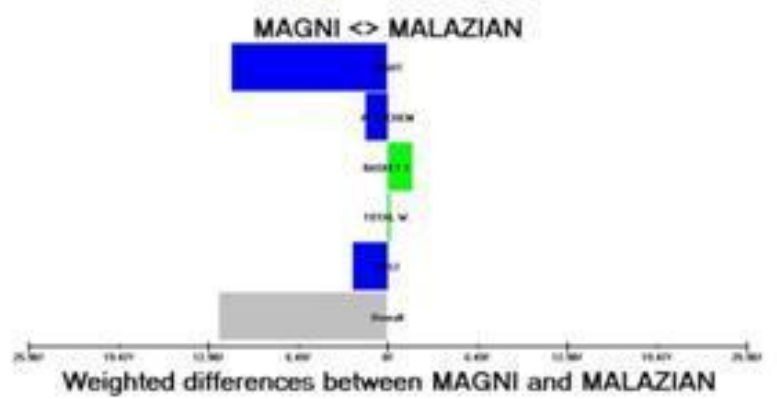

Figure 8:- Compared Machine Weight Difference with Consideration of the Sub-criteria.

The comparison between the Italian and Malaysian lifter machines (Fig.8) revealed the basic difference between them was the height and for cost Magny has more superiority than Malaysian does.

Therefore, based on the survey results, AERI prototype machine has significant economical and technical abilities and for semi-industrial and mass production will be reasonable alternative instead of imported Italian or Malaysian lifters.

\section{Conceptual design of the AERI lifter prototype:-}

Based on the measured data at provincial surveying, which were gained the most proper palm height for the dominant cultivations and the most suitable machine was selected based on the Analytical Hierarchy Process (AHP). So conceptual design of the AERI prototype machine is based on the technical and recorded data and started by modeling MF-399 tractor. It is designed based on the principle of weight transfer from the tractor center of gravity, which located rotating lifter sector to the front of the tractor (2) attached to the chassis (1) and with two links (3 and 4) and using two-way Jack (5) is connected to lifter basket (6). Lifter design is based on the height of 12 meters and the machine will be able to service more than $70 \%$ of date Palms in purposed provinces (Fig. 9 and 10).
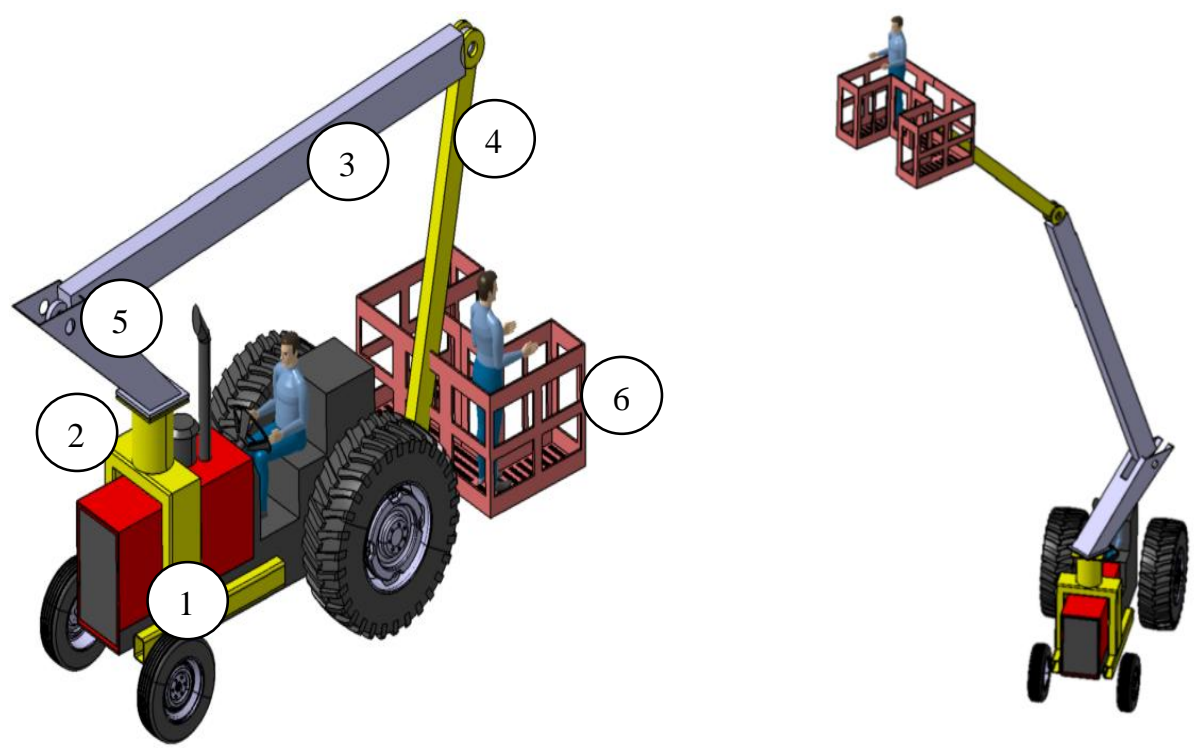

Figure 9:- (a) \& 9(b). Prototype Conceptual Designed Palm Lifter Machine: Left-Transport Form, RightApplication Form.

\section{Conclusion:-}

Province surveying were applied to obtain technical information from current machine in palm cultivation and harvesting application in five provinces and prepared questioner contained palm geometric characteristics. The 
analysis of the measured data indicated that in more than $75 \%$ of the objected provinces of palm orchards (about $140000 \mathrm{ha}$ ), palms have a height of 10 to 12 meters. Based on the analytical hierarchy process (AHP) a proper palm lifter was selected between seven domestic and foreign (imported) machine. The results showed that despite of imported palm lifter (Magny, Italian), AERI prototype lifter is chosen as a proper one. The conceptual design of prototype machine was performed based on recorded information and the machine will be had advantages of existing machinery and lowest disadvantages of them. The prototype machine can service two to four palm trees in one stand to performing cultivation and harvesting dates in different maturity stages.

\section{References:-}

1. “Agricultural Statistics”, Ministry of Agri-Jehad. Available at: http://www.agri-jahad.ir, (2010).

2. A. Aghajani Bazazi, M. Aslanloo and H. Soltan Mohammadi, "Application of multi-criteria decision-making methods in the selection and cargo loading machines Songun Copper Mine", Second conference of mine engineering in Iran-Tehran University, (2008).

3. A. M. Al-khafaf, "Mechanization of palm cultivation and palm processing in Iraq", 3rd FAO tech, (1970).

4. A. Moustafa Fadel, "Development of a tractor-mounted palm tree service machine", Emir. J. Agric. Sci. 2005. 17(2): 30-40, (2005).

5. A. Thwainy, M. Akyurt, and T. M. Abu-Mansour, "Choice a service system for palm trees", Journal of Islamic Academy of Sciences 6:1, 73-81, (1993).

6. G. K. Brown, and R. M. Perkins, "Harvesting Palms Mechanically", Transaction of the ASAE vol. 10, No 4, pp.486-488, (1964).

7. G. K. Brown, and R. M. Perkins, "Mechanical Harvesting of Palms", ASAE paper No. PC-64-8, (1964).

8. J. Bagheri Nejhad and Zh. Adibi, "Integrated model to assess the organization's readiness to implement a data warehouse system using AHP”, Journal - ICT research in Iran, (2010).

9. J. Morshedi,, R. Borna, A. Asghari Poor Dasht Bozorgh, H. Ahmadi and Z. Zaheri Abdeh Vand, "Locating wind power plants using analytic hierarchy process (AHP) in GIS", Journal of Application of remote sensing and GIS in Planning- $1^{\text {st }}$ year, No.2, winter, (2010).

10. K. Shahanaghi, "MODM-based design decisions for the operation and maintenance outsourcing", Department of Industrial Engineering. University of Science and Technology of Iran, (2011).

11. M. Akyurt, E. Rehbini, H. Bogis and A. A. Aljinaidi, "A survey of mechanization efforts on palm crown operations", The $6^{\text {th }}$ Saudi Engineering Conference, KFUPM, Dhahran, (2002).

12. M. Madhoosh, and A. Ashari, "Determine customer needs Iran Khodro Diesel Company using fuzzy AHP approach", Case study (Iran Khodro Diesel company, Bus C457) - Journal of Humanities and Social Sciences$4^{\text {th }}$ year-No. 12, (2004).

13. M. Shamsi, "Design and development of a palm harvesting machine", Unpublished Ph.D. Thesis. Silsoe College, Cranfield University, UK, (2011).

14. R. M. Perkins, and G.K. Brown, "Progress in mechanization of palm harvesting", Palms Growers, Institute report 41; 19-23, P.O. Box 81, Thermal, Calif, (1964).

15. S. Barzghar, M. A. Seifi Monfared and R. Farahani Zanjirani, "A model based on Analytical hierarchy process for the selection of enterprise resource planning systems implementation strategy", Third conference of IT \& Knowledge, Ferdosi Mashhad University, (2007).

16. T. L. Saaty, "How to make a decision: The Analytical Hierarchy Process", Interfaces, 24(6), 19-43, (1994).

17. T. Saaty, "The analytical hierarchical process: planning, priority setting resource allocation", NEW YORK .Mc Graw - Hill, (1980). 